\section{Improving Access to HIV and Sexual Reproductive Health Services for Key Populations along Nigeria's Transport Cor- ridors: The STOP Project}

\author{
Obinna Ositadimma Oleribe ${ }^{1 *}$, Grace lyalla ${ }^{1}$, Ugochinyere \\ Okoro', Chidozie Ezechukwu², Emmanuel Agogo ${ }^{2}$, Olabisi \\ Oladipo $^{5}$, John Idoko ${ }^{2}$ and Simon D Taylor-Robinson ${ }^{3,4}$
}

${ }^{1}$ Excellence and Friends Management Consult (EFMC), Dutse Abuja FCT, Nigeria

${ }^{2}$ National Agency for the Control of AIDS (NACA), Abuja CBD, Nigeria ${ }^{3}$ Royal College of Physicians of London, Regent's Park, London, UK ${ }^{4}$ Faculty of Medicine, Imperial College London, St Mary's Hospital Campus, Norfolk Place, London, UK

${ }^{5}$ Excellence and Friends Management Care Center, Nigeria

\begin{abstract}
Background: Despite high HIV prevalence amongst key populations in strategic travel corridors in Nigeria, there is still very low access to HIV and Sexual Reproductive Health (SRH) services. Targeting men-who-have-sex-with-men, females who sell sex, long distance truck drivers and those who live along the country's transport corridors is vital for effective control of the HIV epidemic in Nigeria. Excellence and Friends Management Consult (EFMC) partnered with the Nigerian National Agency for the Control of AIDS (NACA) to improve access to HIV, SRH services educate and test for HIV, and offer referral/treatment to HIV-infected individuals. We report on the need, process and outcome of this project.

Methods: The Strategic Travelers Outreach Program (STOP) took place between February and August 2016 in Sagamu/Ogere and Obollo-Afor travel corridors. Through community advocacy and outreach, house-to-house, door-to-door and community/office testing, key populations were provided with targeted HIV, SRH and referral services.

Results: Over 50,000 people were contacted with HIV and SRH education/counselling. 19,275 (M: 10,965, 56.9\%; F: 8,310, 43.1\%) were tested with all receiving their results same day. General

*Corresponding author: Obinna Ositadimma Oleribe, Excellence and Friends Management Consult, P.O. Box 200 PSIN Dutse, Dutse Abuja FCT, 901101, Nigeria, Tel: +234 8096083335; E-mail: Obinna.oleribe@expertmanagers.org

Citation: Oleribe OO, lyalla G, Okoro U, Ezechukwu C, Agogo E, et al. (2017) Improving Access to HIV and Sexual Reproductive Health Services for Key Populations along Nigeria's Transport Corridors: The STOP Project. J AIDS Clin Res Sex Transm Dis 4: 011.
\end{abstract}

Received: April 25, 2017; Accepted: June 01, 2017; Published: June 16, 2017 positivity rate was $1.3 \%$ : female $(1.9 \%)$. Brothel-based female sex workers had higher positivity rate $(3.2 \%)$. The study also revealed prostitutes did not use condoms with their husbands or long-term boyfriends and that knowledge of HIV was poor.

Conclusion: The results highlight an urgent need to mobilize educational and healthcare resources to mitigate HIV transmission along these corridors. A socio-anthropological approach is required to alter long-held beliefs and change risk-seeking behavior.

Keywords: Access; EFMC; HIV and AIDS; Key populations; NACA; Nigeria; Sexual and reproductive health; STOP program; Travel corridors

\section{Introduction}

Although HIV is most common among key populations (females who sell sex brothel and non-brothel based), Men-who-have-Sexwith-Men (MSM), People who Inject Drugs (PID), military and paramilitary personnel and long distance drivers; their access to reproductive and sexual health is limited $[1,2]$. Such limitations are also seen among women and men living with HIV as there is little programmatic guidance as to how best ensure access to sexual and reproductive health services [3]. As HIV/AIDS remains a major public health burden around the world, affecting over 36 million people and leading to the death of about 34 million people, there has been an increasing awareness and discussion of the benefits of linkage between Sexual Reproductive Health (SRH) and HIV programs at the policy, systems and service delivery levels [4,5]. Moreover, in 2010, HIV/AIDS was reported as having the $5^{\text {th }}$ largest associated Disability-Adjusted Life Year (DALY) measurement - a measure of overall disease burden, expressed as the number of years lost due to ill-health, disability or early death. HIV had the most prominent DALY association for people of both sexes, aged from 30-44 years in Eastern, Southern and Central Africa, the Caribbean and Thailand [6]. On that background, HIV has remained one of the most important communicable diseases in Nigeria, affecting close to 3.5 million people with about 1,476,741 requiring Anti-Retroviral Drugs (ARV) in 2013 [7].

Despite a seeming decline in HIV prevalence, the burden of HIV disease is disproportionately high among key populations, such as females who sell sex, men-who-have-sex-with-men, people who inject drugs and long distance transport workers where rates have remained relatively high with spikes in incidence across the world [8-10]. In Nigeria, the Integrated Biological and Behavioral Surveillance Survey (IBBBS) study revealed that Men-who-have-Sex-with-Men (MSM) have the highest prevalence of $22.9 \%$, followed by Brothel-Based Females Who Sell Sex (BBFWSS) with 19.4\% prevalence, Non-BrothelBased Females Who Sell Sex, (NBBFWSS) at $8.6 \%$ and long distance truck drivers, who had the lowest prevalence of the at-risk populations at $1.6 \%$ [11]. Some of the factors which increase the vulnerability of these groups to HIV infection and maintenance of the epidemic at the population level include risky sexual behavior, current sex-work laws and enforcement-based policies, poor perception of HIV risk, poverty, ineffective STI programming, poor integration of HIV/AIDS and sexual and reproductive health services and gender inequality $[12,13]$.

Furthermore, key populations have remain highly stigmatized and are unable to access appropriate health care services or exercise their 
rights to health due to legal restrictions, discrimination and society mediated violence [14]. For instance, in Nigeria, sex trade is an illegal trade and practitioners are criminalized; and when seen, they are arrested, required to either pay fine for their release (bail) and spend some time in prison/detention $[15,16]$. In the midst of the current global economic recession, it is important to track the magnitude of the HIV/AIDS epidemic, its drivers and consequences, to allocate efficiently the limited resources and to maintain funding for effective HIV/AIDS interventions and treatments [6]. In Nigeria, a particular focus for disease transmission is the "travel corridor", which is a resting zone along the long distance high traffic motorways, where travelers stop for rest, refreshment and ad hoc purchases, before continuing to their final destinations. To track the epidemic, the Nigerian National Agency for the Control of AIDS (NACA) conducted a travel corridor assessment and mapping exercise in 2013, which revealed the need for a specific travel corridor project to assess the microculture and HIV disease prevalence in these communities [17]. The goal of this project was to improve the access of key populations to reproductive and sexual health along two travel corridors in Nigeria.

\section{Methodology}

\section{Pre-project activities}

The National Agency for the Control of AIDS (NACA) in Nigeria contracted Excellence and Friends Management Consult (EFMC) to execute the Travel Corridor Prevention Initiative (TCPI) in Sagamu (Ogun State, South West Nigeria) and Obollo-Afor (Enugu State, South East Nigeria) Travel Corridors in 2016 (Figure 1). We signed a 6 months' contract with NACA in Abuja, Nigeria in early 2016, developed strategies and operational guidelines and a standard operating procedure using a minimum prevention package initiative [14]. In addition, office and staff accommodation spaces were secured and equipped. Three full time staff and several volunteers were identified, shortlisted, interviewed and engaged. Banners and fliers were designed, developed, pre-tested and mass produced for the project (Figure 2). Community gatekeepers such as community, religion, market women, Brothel-Based Females Who Sell Sex (BBFWSS), Long Distance Drivers (LDD), commercial motorcycle riders, street traders, the police, Federal Road Safety Commission (FRSC), the National Civil Defense Corps and road traffic union leaders were identified, interviewed, their views sought and engaged.

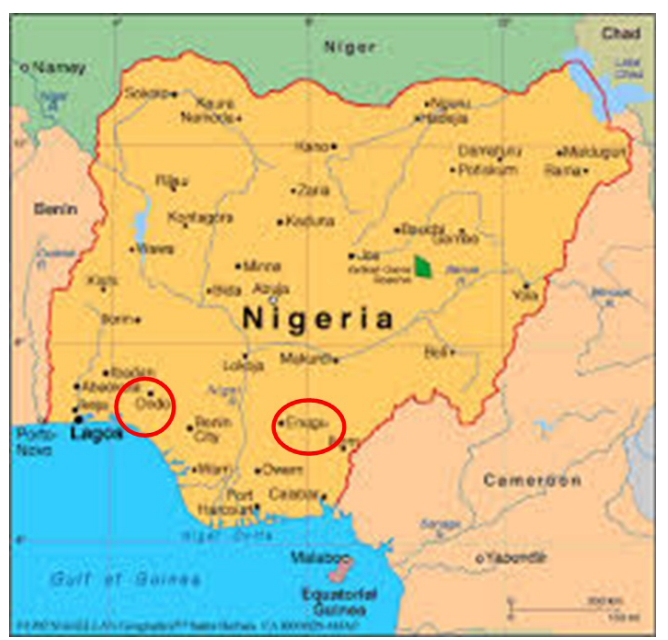

Figure 1: Map of Nigeria showing the location of the STOP project in Sagamu and Obollo-Afor in South West and South East Nigeria.

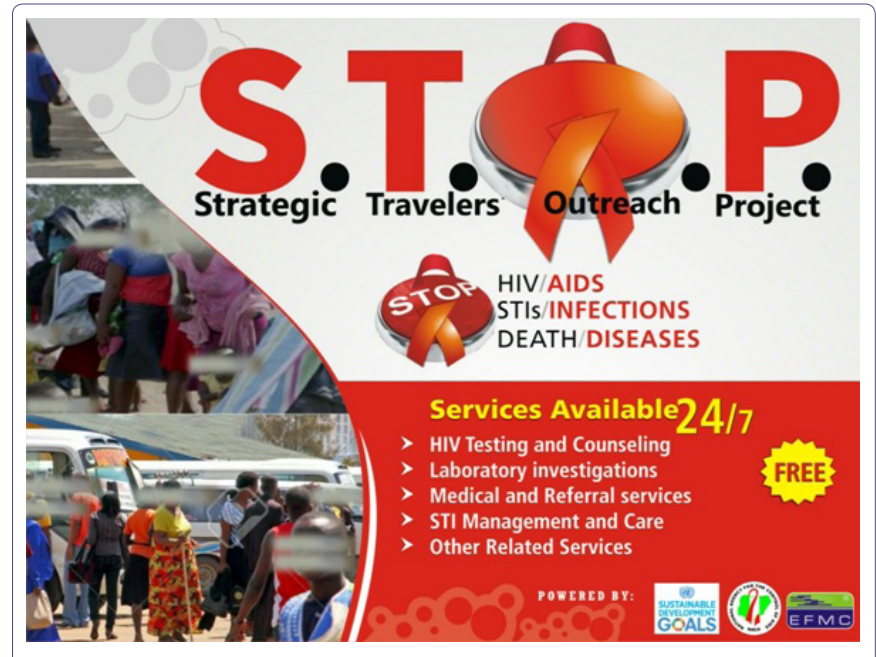

Figure 2: STOP banner pretested and approved for the Sagamu and Obollo-Afor project, 2016.

Permission to execute the work was sought and obtained from appropriate state, institutional and local government authorities. HIV Rapid Diagnostic Kits, information bulletins and fliers and condoms were sourced from NACA and shipped to Sagamu and Obollo-Afor. Startup meetings were held in Abuja, Sagamu and Obollo-Afor. Information, Education and Communication (IEC) materials were produced and distributed.

\section{Project areas}

Site 1:

Sagamu: Sagamu Local Government Area in Ogun State is bordered to the north by Ikenne LGA, to the west by Obafemi Owode LGA, to the South by Lagos State and to the East by Odogbolu LGA [17]. The LGA covers a total land area of $614 \mathrm{~km}^{2}$ (237 sq). Sagamu LGA has a total population of 253,412 in the 2006 census. The major occupation of people with the local government area includes agriculture, trading and transportation. Agricultural products in Sagamu include cocoa and kola nut, with the largest kola nut collection and distribution center in Nigeria. Sagamu has major mineral deposits of limestone, housing the West African Portland cement industry (Lafarge). Along the transport corridor in Sabo, Isale-Oko, Awolowo, Kara and WAPCO are transport workers, females who sell sex, road side traders, allied workers (mechanics and electricians), etc., [17]. Apart from a teaching hospital, the other healthcare facilities are primary healthcare centers. Stigma, discrimination and criminalization of sex trade and drug use hinders access to healthcare for those most in need.

Site 2:

Obollo-Afor: Obollo-Afor is the head quarter of Udenu LGA and is situated at the regional boundary between the South-East and North-Central geopolitical zones of the country [17]. Obollo-Afor has mostly farmers and traders as inhabitants. The traders sell mostly locally made and harvested farm products such as cassava, yams, cocoyam, cashew and palm kernels. The Afor market of Obollo-Afor runs every four days and is highly patronized by people from the northern and southern regions of the country. This makes Obollo-Afor a very busy travel corridor linking northern Nigeria to the south. However, healthcare services are scarce as the only secondary care center is in another community. 


\section{Project activities}

This project took place between March-August 2016. A scoping visit was carried out in March 2016 and office space was identified (Figure 3). We staffed and equipped the two project offices. Our key staff from Abuja trained both new officers and volunteers on Reproductive and Sexual Health (RSH), HIV testing and counselling and community programming. The training curriculum covered relevant health issues such as safe sexual habits, defensive driving techniques and use of personal protective equipment for drivers and commercial motor cycle (Okada) riders and healthy marketing behavior and attitudes. We provided HIV Testing and Counseling (HTC), free condoms and referral for those with HIV positive results to treatment sites within the region. Also, we provided free medical examinations including blood pressure checks, blood glucose testing and doctors' consultations. The inaugural program was held at both locations and the project was named STOP (Strategic Travelers Outreach Project). Sexual and Reproductive Health (SRH) services were provided at the project office and within the communities. To reach all, houseto-house, door-to-door and shop-to-shop strategies were deployed with staff and volunteers meeting people where they lived or worked. We enlisted everybody seen along the travel corridors on work days (Monday-Saturday) who gave their consent and those that came to the project office every day. Project data were entered into MS Excel and analyzed.

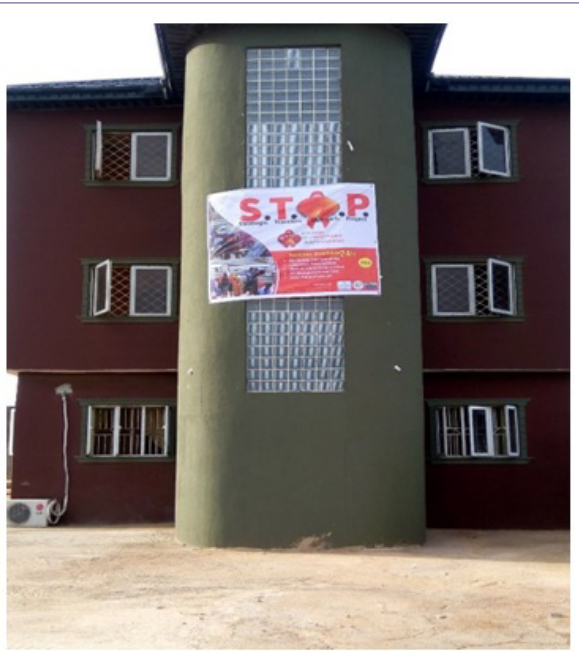

Figure 3: Office of STOP project, Sagamu, Ogun State, Nigeria.

\section{Qualitative studies}

Over 100 gatekeepers including community, religious groups, market women, BBFWSS, LDDs, commercial motorcycle riders, street traders, the police, National Road Safety Commission, National Civil Defense Corps, and road traffic union leaders, representing the target population were identified and interviewed. Females who sell sex were also interviewed on their sexual habits, knowledge of HIV and AIDS and prevention practices.

\section{Results}

Over 50,000 people drawn from LDDs, commercial motorcycle riders, street traders, market women, military and paramilitary personnel, BBFWSS and all STOP club members were reached through the STOP project and provided with reproductive and sexual education, support and guidance. Out of this, 19,275 persons $(M=10965$, $56.9 \% ; \mathrm{F}=8310,43.1 \%)$ people within the travel corridor were tested for HIV infection and received their results. In addition, 422 people were trained on SRH, safe driving practices, first aid management and other related topics resulting in the establishment of the STOP clubs in both travel corridors. Of 19,275 tested, 243 (1.3\%) were positive for HIV. Higher positivity rate was seen among females $(113,1.8 \%)$ as compared to males $(41,0.8 \%)$. Males and Females from Sagamu had higher positively that those in Obollo-Afor (Table 1). In Sagamu travel corridor, activities took place in two separate locations-Sagamu town and Ogere. Overall positivity rate out of 9606 persons tested in this location was $1.8 \%$. Females Who Sell Sex (FWSS) had the highest positivity rate of $7.2 \%$ with Ogere having a higher rate of $7.8 \%$ as against Sagamu's 6.5\% (Table 2). Similar reports was seen in Obollo-Afor where FWSS had the highest positivity rate, followed by military and paramilitary persons as shown in table 2. Among 220 key stakeholders tested in Obollo-Afor, $4.5 \%$ were positive for HIV. Females who sell sex also had the highest positivity rate $(33.3 \%)$ as shown in table 3 .

\begin{tabular}{|c|c|c|c|c|c|c|}
\hline & \multicolumn{2}{|c|}{ Male } & \multicolumn{2}{c|}{ Female } & \multicolumn{2}{c|}{ Total } \\
\hline Location & Tested & Positive & Tested & Positive & Tested & Positive \\
\hline Sagamu & 5,594 & $\begin{array}{c}57 \\
(1.0 \%)\end{array}$ & 4013 & $\begin{array}{c}113 \\
(2.8 \%)\end{array}$ & 9,607 & $\begin{array}{c}170 \\
(1.8 \%)\end{array}$ \\
\hline Obollo-Afor & 5,371 & $\begin{array}{c}32 \\
(0.6 \%)\end{array}$ & 4297 & $\begin{array}{c}41 \\
(1.0 \%)\end{array}$ & 9,668 & $\begin{array}{c}73 \\
(0.8 \%)\end{array}$ \\
\hline Total & 10,965 & $\begin{array}{c}89 \\
(0.8 \%)\end{array}$ & 8,310 & $\begin{array}{c}154 \\
(1.9 \%)\end{array}$ & 19,275 & $\begin{array}{c}243 \\
(1.3 \%)\end{array}$ \\
\hline
\end{tabular}

Table 1: Travel corridor HIV test results.

Generally, people aged 25-49 years-old had the highest positivity rate (2.4\%). In Ogere alone, those within the age bracket $20-24$ years had a higher prevalence rate of $3.9 \%$, as against $3.8 \%$ for those 25 49 years (Table 4). A similar finding was made in Obollo-Afor where persons aged 25-29 years had the highest age specific positivity rate (Table 5).

Interviews of FWSS revealed that they did not use condoms with their husbands or long-term boyfriends. Also, their knowledge of HIV transmission risk was poor as less than $10 \%$ had a good understanding of the real meaning of HIV, transmission channels and prevention strategies. Unstandardized interviews of some FWSS revealed that a number of them knew their status (some for over 3 years), were already on antiretroviral medications or had stopped their medications because of lack of access to antiretroviral therapy (as some moved out from their previous locations to seek acceptance in new locations). Also, a number of them were married with grown-up children, had boyfriends with whom they do not use condoms and were unwilling to share their positive HIV status with their partners, clients and boyfriends. Finally, less than $10 \%$ of all those surveyed had adequate knowledge of HIV, its origin, channels of transmission and control strategies.

\section{Discussion}

The project improved access to reproductive and sexual health for over 50,000 people who were reached with sexual health education, free condoms, HIV testing and counselling, and management of sexually transmitted diseases. Of the over 19,000 people tested in the two travel corridors, $1.3 \%$ were positive for HIV with a higher prevalence in the Sagamu travel corridor that links the South-West to the Northern part of Nigeria. The $1.3 \%$ overall prevalence was similar to the $1.3 \%$ for Enugu State reported by the National HIV\&AIDS and Reproductive Health Survey, but higher than the 0.6\% reported for 
Citation: Oleribe OO, Iyalla G, Okoro U, Ezechukwu C, Agogo E, et al. (2017) Improving Access to HIV and Sexual Reproductive Health Services for Key Populations along Nigeria's Transport Corridors: The STOP Project. J AIDS Clin Res Sex Transm Dis 4: 011.

- Page 4 of 6 •

\begin{tabular}{|c|c|c|c|c|c|c|c|c|}
\hline \multirow[t]{2}{*}{ Description } & \multicolumn{2}{|c|}{ Ogere } & \multicolumn{2}{|c|}{ Sagamu } & \multicolumn{2}{|c|}{ Total } & \multicolumn{2}{|c|}{ Obollo-Afor } \\
\hline & Tested & Positive & Tested & Positive & Tested & Positive & Tested & Positive \\
\hline Touts (Agbero) & 6 & $0(0.0 \%)$ & 293 & $2(0.7 \%)$ & 299 & $2(0.0 \%)$ & 300 & $4(1.3 \%)$ \\
\hline Long Distant Drivers & 2195 & $29(1.3 \%)$ & 809 & $18(2.2 \%)$ & 3004 & $47(1.6 \%)$ & 1400 & $10(0.7 \%)$ \\
\hline $\begin{array}{l}\text { Commercial Moto Cycle } \\
\text { (Okada) Riders }\end{array}$ & 955 & $0(0.0 \%)$ & 1110 & $2(0.2 \%)$ & 2065 & $2(0.1 \%)$ & 2200 & $10(0.45 \%)$ \\
\hline $\begin{array}{c}\text { Hawkers/Market Women } \\
\text { \&Men }\end{array}$ & 448 & $22(4.9 \%)$ & 1998 & $31(1.6 \%)$ & 2446 & $53(2.2 \%)$ & 4040 & $27(0.67 \%)$ \\
\hline Females who sell sex & 306 & $24(7.8 \%)$ & 309 & $20(6.5 \%)$ & 615 & $44(7.2 \%)$ & 320 & $6(1.9 \%)$ \\
\hline $\begin{array}{l}\text { Military and paramilitary } \\
\text { personnel }\end{array}$ & 23 & $0(0.0 \%)$ & 106 & $0(0.0 \%)$ & 129 & $0(0.0 \%)$ & 54 & $1(1.8 \%)$ \\
\hline $\begin{array}{c}\text { Travellers and General } \\
\text { Population }\end{array}$ & 203 & $3(1.5 \%)$ & 845 & $23(2.2 \%)$ & 1048 & $23(2.2 \%)$ & 1354 & $15(1.11 \%)$ \\
\hline
\end{tabular}

Table 2: Sagamu/Ogere and Obollo-Afor travel corridor report, 2016.

\begin{tabular}{|c|c|c|c|}
\hline Description & Tested & Positive & Positivity Rate \\
\hline $\begin{array}{c}\text { Long Distant Drivers } \\
\text { Commercial Motor Cylce (Okada) } \\
\text { Riders }\end{array}$ & 63 & 2 & 3.2 \\
\hline Hawkers/Market Women & 34 & 3 & 3.9 \\
\hline Military and Paramilitary Personnel & 44 & 1 & 8.8 \\
\hline Female who sell sex & 6 & 2 & 3.3 \\
\hline Total & 220 & 10 & $4.5 \%$ \\
\hline
\end{tabular}

Table 3: Positivity rate among Obollo-Afor key stakeholders, 2016.

\begin{tabular}{|c|c|c|c|c|c|c|}
\hline & \multicolumn{2}{|c|}{ Ogere } & \multicolumn{2}{c|}{ Sagamu } & \multicolumn{2}{c|}{ Total } \\
\hline $\begin{array}{c}\text { Age } \\
\text { group }\end{array}$ & Tested & Positive & Tested & Positive & Tested & Positive \\
\hline $0-14$ & 112 & $1(0.9 \%)$ & 688 & $3(0.4 \%)$ & 800 & $4(0.5 \%)$ \\
\hline $15-19$ & 194 & $2(1.0 \%)$ & 751 & $4(0.5 \%)$ & 945 & $6(0.6 \%)$ \\
\hline $20-24$ & 463 & $18(3.9 \%)$ & 987 & $2(0.2 \%)$ & 1450 & $20(1.4 \%)$ \\
\hline $25-49$ & 1430 & $54(3.8 \%)$ & 4024 & $76(1.9 \%)$ & 5454 & $130(2.4 \%)$ \\
\hline$>49$ & 113 & $3(2.7 \%)$ & 844 & $8(0.9 \%)$ & 957 & $11(1.1 \%)$ \\
\hline Total & 2312 & $78(3.4 \%)$ & 7295 & $93(1.3)$ & 9606 & $171(1.8 \%)$ \\
\hline
\end{tabular}

Table 4: Testing report disaggregated by Age for Sagamu/Ogere travel corridor.

\begin{tabular}{|c|c|c|c|c|}
\hline & \multicolumn{2}{|c|}{ Males } & \multicolumn{2}{c|}{ Females } \\
\hline Age Group & Tested & Positive (\%) & Tested & Positive (\%) \\
\hline $0-14$ & 715 & $4(0.6 \%)$ & 816 & $1(0.1 \%)$ \\
\hline $15-19$ & 1168 & $4(0.3 \%)$ & 1189 & $4(0.3 \%)$ \\
\hline $20-24$ & 1804 & $4(0.2 \%)$ & 1463 & $21(1.4 \%)$ \\
\hline $25-49$ & 6393 & $63(1.0 \%)$ & 3985 & $124(3.1 \%)$ \\
\hline$>49$ & 885 & $11(1.2 \%)$ & 857 & $8(0.9 \%)$ \\
\hline Total & 10965 & $86(0.8 \%)$ & 8310 & $158(1.9 \%)$ \\
\hline
\end{tabular}

Table 5: Sagamu/Ogere and Obollo-Afor testing results disaggregated according to Age, 2016.

Ogun State by the same report [18]. The individual travel corridors positivity rates of $1.8 \%$ for Sagamu/Ogere and $0.8 \%$ for Obollo-Afor showed significant reversal when compared with the state figures from the above study of $0.6 \%$ and $1.3 \%$ for Ogun and Enugu States respectively. However, as the individuals in these travel corridors represent people of the various geopolitical zones, the findings were similar to the zonal reports which indicates that prevalence in the South-West of Nigeria is higher than that of the South East (2.8 vs 1.8\%) [18].

The FWSS had the highest prevalence of $7.8 \%$ in Ogere, $6.5 \%$ in Sagamu and $1.9 \%$ in Obollo-Afor while military and paramilitary personnel had the lowest positivity rate in Sagamu/Ogere axis but higher rates in Obollo-Afor. These finding are in line with the recent Nigerian study which showed an overall HIV prevalence among the target groups of $9.5 \%$ with the highest prevalence seen among MSM (22.9\%), followed by brothel based females who sell sex (19.4\%), non-brothel based females who sell sex (8.6\%), people who inject drugs (3.4\%), police (2.5\%), transport workers (1.6\%) and armed forces (1.5\%) [11]. A field study by EFMC in 2012 showed a similar high prevalence among females who sell sex with some brothel based females who sell sex having positivity rate of over $50 \%$ [19].

The different positivity rate among the military and paramilitary groups in both regions may reflect their higher level of mobility in the Nigerian South East, compared to the South-West zone. Also, there was no identifiable pattern for the positively rates seen in the rest of the key populations. This calls for a more detailed controlled study to uncover the sociological factors responsible for the current positive rates seen in the communities. During the project, it was found that FWSS were not disclosing their status, not even to their long-term boyfriends. The non-disclosure of status by FWSS shows the dangers men face when they patronize FWSS. This risk is high as studies have shown prevalence rates of up to $50 \%$ among BBFWSS [11,19]. What is more disturbing is the fact that some male customers pay extra money to the FWSS for sex without condoms, a practice that increases the possibility of new or multiple infection(s). The high HIV positivity level seen in travelers along the Obollo-Afor corridor is another issue of concern, as recent studies show a rising prevalence in Anambra (from $8.7 \%$ in 2010 to $9.7 \%$ in 2014 ) and Imo (3.0\% to $7.5 \%$ ) States, but a slightly reducing prevalence in the other States in the South East of Nigeria, including Enugu State, which decreased from 5.1\% in 2010 to $4.9 \%$ in $2014[20,21]$. If the majority of those with HIV were traveling to the region (this was not studied in this work), the region may be at the risk of rising prevalence, if nothing is done.

More males were found to be reactive early in life (2.7\%). Prevalence among the various sex groups gradually decreased until 20-24 years and begins to rise again (Table 5 and Figure 4). Among females, the trend was different. Females aged 0-14 years had the lowest HIV rate, but the rate increases in a linear pattern over the age-groups considered up to 25-49 years and then began to decline (Figure 4). This study, therefore, observed that more males were found to be 
Citation: Oleribe OO, Iyalla G, Okoro U, Ezechukwu C, Agogo E, et al. (2017) Improving Access to HIV and Sexual Reproductive Health Services for Key Populations along Nigeria's Transport Corridors: The STOP Project. J AIDS Clin Res Sex Transm Dis 4: 011.

HIV-infected at younger ages, with HIV prevalence decreasing up to 25 years, then increasing after 25 years of age. With females, the HIV prevalence increased gradually increases up to 49 and by 50 years and above, began to decline. An STI screening and HTC conducted among FWSS at other locations in Enugu State in 2016 showed that HIV prevalence was highest among those aged 25-49 [21]. Beyond sexual exposure, the factors behind this trend are not immediately apparent. The reason for this trend will need further exploration and thus will require future expanded qualitative studies. Refusal to disclose HIV status, even to close sexual partners, can negatively affect the overall outcome of any control measure. Working to improve their HIV knowledge will facilitate control efforts.

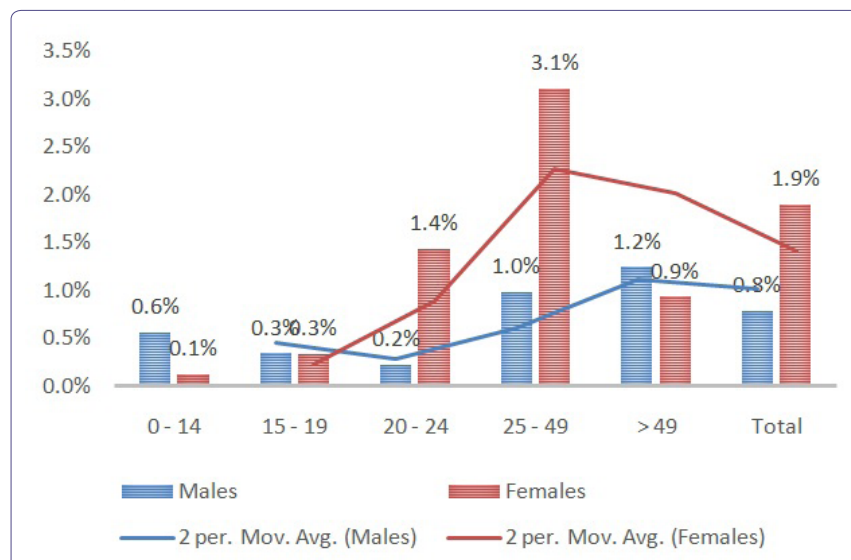

Figure 4: HV positive trend among male and females tested in Sagamu and Obollo-Afor, May-August 2016.

\section{Limitations}

This study may have suffered from self-selection bias as some who already knew their HIV status may have opted out from the exercise $[22,23]$. If this is the case, the positivity rate in this report may not be representative of the population studies.

\section{Conclusion}

HIV remains a major communicable health challenge in Nigeria, especially among the key populations such as females who sell sex and long distance travelers. As there are few programs targeting the informal sectors, coupled with limited access to other reproductive and sexual health services, these hotspots will remain a major cause of concern in the control of HIV epidemic until active steps are taken to reduce infections and provide compressive care and support in a sustainable manner. Expanding the STOP project may therefore be a step in the right direction.

\section{Recommendations}

Access to sexual and reproductive healthcare services should be improved upon for key populations especially those in high and strategic traffic travel corridors like Obollo-Afor and Sagamu/Ogere axis. Beyond behavioral change and STI/HCT interventions, STOP should be funded to provide anti-retroviral therapy services as this will minimize loss to follow-up. This will accelerate Nigeria's progress towards the 90-90-90 target by 2020 and contribute to slowing the rate of new HIV infections. There is a need to institutionalize travel corridor projects in all key travel corridors in Nigeria by ensuring it is reflected in the forthcoming Nigerian National HIV/AIDS Strategic Plan. The Nigerian government and development partners should mobilize resources to stop HIV transmission in these marginalized key communities through community targeted projects. Finally, there is the need to utilize socio-anthropological approaches to change the behavior of people in Nigeria towards HIV prevention in Nigeria.

\section{References}

1. WHO (2014) Consolidated guidelines on HIV prevention, diagnosis, treatment and care for key populations. WHO, Geneva, Switzerland.

2. Dellar RC, Dlamini S, Karim QA (2015) Adolescent girls and young women: key populations for HIV epidemic control. J Int AIDS Soc 18: 19408.

3. Gruskin S, Ferguson L, O'Malley J (2007) Ensuring sexual and reproductive health for people living with HIV: an overview of key human rights, policy and health systems issues. Reprod Health Matters 15: 4-26.

4. Kennedy CE, Spaulding AB, Brickley DB, Almers L, Mirjahangir J, et al. (2010) Linking sexual and reproductive health and HIV interventions: a systematic review. J Int AIDS Soc 13: 26.

5. WHO (2016) Global Health Observatory (GHO) data. HIVIAIDS, WHO, Geneva, Switzerland.

6. Ortblad KF, Lozano R, Murray CJ (2013) The burden of HIV: insights from the Global Burden of Disease Study 2010. AIDS 27: 2003-2017.

7. National Agency for the Control of AIDS (NACA) (2014) Federal Republic of Nigeria Global AIDS Response Country Progress Report, Abuja, Nige-

8. Baral S, Beyrer C, Muessig K, Poteat T, Wirtz AL, et al. (2012) Burden of HIV among female sex workers in low-income and middle-income countries: a systematic review and meta-analysis. Lancet Infect Dis 12: 538-549.

9. Beyrer C, Abdool Karim Q (2013) The changing epidemiology of HIV in 2013. Curr Opin HIV AIDS 8: 306-310.

10. Wolf RC, Cheng AS, Kapesa L, Castor D (2013) Building the evidence base for urgent action: HIV epidemiology and innovative programming for men who have sex with men in sub-Saharan Africa. J Int AIDS Soc 16: 18903.

11. Federal Ministry of Health (2015) Integrated Biological and Behavioral Surveillance Survey (IBBSS) 2014. National HIVIAIDS \& STIs Control Programme, Abuja FCT Nigeria, Nigeria.

12. Shannon K, Strathdee SA, Shoveller J, Rusch M, Kerr T, et al. (2009) Structural and environmental barriers to condom use negotiation with clients among female sex workers: implications for HIV-prevention strategies and policy. Am J Public Health 99: 659-665.

13. Kasedde S, Luo C, McClure C, Chandan U (2013) Reducing HIV and AIDS in adolescents: opportunities and challenges. Curr HIVIAIDS Rep 10: 159-168.

14. NACA (2013) Minimum Prevention Package Intervention (MPPI): A simple Implementation Guide. NACA, Government of Nigeria, Abuja, Nigeria.

15. Harcourt C, Egger S, Donovan B (2005) Sex work and the law. Sex Health 2: $121-128$

16. Izugbara OC (2010) 'Ashawo suppose shine her eyes': Female sex workers and sex work risks in Nigeria. Health, Risk \& Society 7: 141-159.

17. NACA (2013) Nigerian Transport Corridor Project: Mapping of selected locations. NACA/MDG Supported Transport Corridor Project.

18. Federal Ministry of Health (2013) National HIV and AIDS and Reproductive Health Survey (NARHS Plus II, 2012). Federal Republic of Nigeria, Federal Ministry of Health, Abuja, Nigeria.

19. Oleribe OEO, Fasuba M, Osita-Oleribe PI, Udoh PU, Nwachukwu EC (2013) Targeting Most at Risk Populations (MARPS) and HIV Prevalence in North-Central Nigeria. 29th National Scientific and Annual general meeting of Association of Public Health Physicians of Nigeria (APHPN), Ilorin, Kwara, Nigeria. Pg no: 20. 
Citation: Oleribe OO, Iyalla G, Okoro U, Ezechukwu C, Agogo E, et al. (2017) Improving Access to HIV and Sexual Reproductive Health Services for Key Populations along Nigeria's Transport Corridors: The STOP Project. J AIDS Clin Res Sex Transm Dis 4: 011.

- Page 6 of 6 •

20. Federal Ministry of Health (2015) 2014 National HIV Sero-prevalence - Sentinel Survey among Pregnant Women Attending Antenatal Clinics in Nigeria National AIDS/STI Control Programme, Federal Ministry of Health, Abuja FCT Nigeria, Nigeria.

21. NACA (2016) Demand Creation for STI services and management of Sexually Transmitted Infections among High Risk Women and Vulnerable Girls in selected High Burden States: Report of Enugu State Intervention, Nigeria.
22. Heckman JJ (2010) Selection bias and self-selection. In: Durlauf SN, Lawrence E. Blume (eds.). Microeconometrics. Palgrave Macmillan, Basingstoke, UK. Pg no: 242-266.

23. Nilsen RM, Vollset SE, Gjessing HK, Skjaerven R, Melve KK, et al. (2009) Self-selection and bias in a large prospective pregnancy cohort in Norway. Paediatr Perinat Epidemiol 23: 597-608. 